\title{
High-resolution optical constants of crystalline ammonium nitrate for infrared remote sensing of the Asian Tropopause Aerosol Layer
}

\author{
Robert Wagner $^{1}$, Baptiste Testa ${ }^{2}$, Michael Höpfner ${ }^{1}$, Alexei Kiselev ${ }^{1}$, Ottmar Möhler ${ }^{1}$, Harald Saathoff ${ }^{1}$, \\ Jörn Ungermann ${ }^{3}$, and Thomas Leisner ${ }^{1}$ \\ ${ }^{1}$ Institute of Meteorology and Climate Research, Karlsruhe Institute of Technology, Karlsruhe, Germany \\ ${ }^{2}$ Department of Physics and Chemistry, University of Lyon, Lyon, France \\ ${ }^{3}$ Institute of Energy and Climate Research, Stratosphere, Forschungszentrum Jülich, Jülich, Germany
}

Correspondence: Robert Wagner (robert.wagner2@kit.edu)

Received: 29 June 2020 - Discussion started: 12 August 2020

Revised: 19 January 2021 - Accepted: 22 January 2021 - Published: 11 March 2021

\begin{abstract}
Infrared spectroscopic observations have shown that crystalline ammonium nitrate (AN) particles are an abundant constituent of the upper tropospheric aerosol layer which is formed during the Asian summer monsoon period, the so-called Asian Tropopause Aerosol Layer (ATAL). At upper tropospheric temperatures, the thermodynamically stable phase of $\mathrm{AN}$ is different from that at $298 \mathrm{~K}$, meaning that presently available room-temperature optical constants of AN, that is, the real and imaginary parts of the complex refractive index, cannot be applied for the quantitative analysis of these infrared measurements. In this work, we have retrieved the first low-temperature data set of optical constants for crystalline $\mathrm{AN}$ in the $800-6000 \mathrm{~cm}^{-1}$ wavenumber range with a spectral resolution of $0.5 \mathrm{~cm}^{-1}$. The optical constants were iteratively derived from an infrared extinction spectrum of $1 \mu \mathrm{m}$ sized AN particles suspended in a cloud chamber at $223 \mathrm{~K}$. The uncertainties of the new data set were carefully assessed in a comprehensive sensitivity analysis. We show that our data accurately fit aircraft-borne infrared measurements of ammonium nitrate particles in the ATAL.
\end{abstract}

\section{Introduction}

The term "Asian Tropopause Aerosol Layer" (ATAL) was established in 2011 when analyses of CALIPSO lidar measurements revealed the existence of a layer of enhanced aerosol concentrations at altitudes from 13 to $18 \mathrm{~km}$ during the Asian summer monsoon (Vernier et al., 2011). The formation of the ATAL is related to the strong convection within the Asian monsoon system, leading to the transport of boundary layer pollutants to the tropical tropopause layer (Vernier et al., 2018). Since its original discovery, the ATAL has been investigated by a variety of balloon-borne, aircraft-borne, and long-term satellite measurements (Höpfner et al., 2019; Lau et al., 2018; Thomason and Vernier, 2013; Vernier et al., 2018, 2015; Yu et al., 2017). Additionally, chemical transport models have been used to simulate the chemical composition and concentration of aerosol particles lifted to and formed in the ATAL (Fairlie et al., 2020; Gu et al., 2016).

The model simulations predicted that nitrate aerosol is a prominent constituent of the ATAL. Ion chromatographic analyses of filter samples collected during the BATAL campaigns (balloon measurements of the ATAL) (Vernier et al., 2018), as well as in situ aerosol mass spectrometer measurements during high-altitude research aircraft flights within the StratoClim project (stratospheric and upper tropospheric processes for better climate predictions) (Höpfner et al., 2019), confirmed the presence of nitrate aerosol particles. Another important step forward in understanding the chemical composition of the ATAL was made by the analysis of infrared limb observations from various satellite missions dating back as far as 1997 and from the abovementioned StratoClim research flights over Nepal and India in 2017 (Höpfner et al., 2019). A distinct infrared signature at $831 \mathrm{~cm}^{-1}$ with a width of about $3 \mathrm{~cm}^{-1}$, consistently observed for spectra 
recorded in the ATAL during the Asian summer monsoon, was ascribed to the $v_{2}\left(\mathrm{NO}_{3}^{-}\right)$mode of crystalline ammonium nitrate (AN), suggesting that $\mathrm{AN}$ is a ubiquitous part of the ATAL. The presence of $\mathrm{NH}_{3}$ in the upper troposphere during the Asian summer monsoon, as required for the neutralization of nitric acid and the formation of AN particles (Wang et al., 2020), had already been detected by previous satellite observations (Höpfner et al., 2016).

To support the interpretation of the satellite and aircraftbased infrared measurements, laboratory infrared extinction spectra of crystalline AN particles and supercooled aqueous AN solution droplets have been recorded at temperature conditions of the upper troposphere in the aerosol and cloud simulation chamber AIDA (Aerosol Interaction and Dynamics in the Atmosphere) (Höpfner et al., 2019). These measurements confirmed that the signature at $831 \mathrm{~cm}^{-1}$ is due to AN particles in the crystalline state, because the respective $v_{2}\left(\mathrm{NO}_{3}^{-}\right)$mode of supercooled aqueous AN solution droplets is shifted to $829 \mathrm{~cm}^{-1}$ and has a larger width of about $6 \mathrm{~cm}^{-1}$ (Höpfner et al., 2019). The crystallization of AN from aqueous AN solution droplets can be induced by various heterogeneous mechanisms, including contact efflorescence (Davis et al., 2015), inclusion of insoluble dust grains (Han et al., 2002), or admixing small amounts of ammonium sulfate (AS), which precipitates first and triggers the crystallization of AN (Schlenker et al., 2004; Schlenker and Martin, 2005). The phase state of AN is crucial for predicting the impact that particles will have on cloud formation in the upper troposphere. Whereas supercooled aqueous AN solution droplets only favor cirrus formation by homogeneous ice nucleation (Cziczo and Abbatt, 2001; Koop et al., 2000), crystalline AN particles induce heterogeneous ice formation at much lower relative humidities compared to homogeneous freezing conditions (Shilling et al., 2006; Wagner et al., 2020).

To enable the quantitative analysis of the infrared limb observations with respect to the total mass of AN, the infrared $v_{2}\left(\mathrm{NO}_{3}^{-}\right)$mode recorded in the AIDA chamber has been scaled by the particles' mass concentration to yield mass-specific absorption coefficients (Höpfner et al., 2019). More versatile input parameters for the accurate retrieval of aerosol parameters from infrared remote sensing measurements are the so-called optical constants, that is, the real and imaginary parts of the complex refractive index (Bohren and Huffman, 1983; Zasetsky et al., 2007). To date, there exists only one data set of the complex refractive index of solid ammonium nitrate at infrared wavelengths (Jarzembski et al., 2003). The data were derived from the analysis of roomtemperature infrared spectra of AN compiled in a spectroscopic library, measured using powders dispersed in an inert paraffin oil. For two reasons, however, this data set cannot be applied for the analysis of the infrared limb observations of the ATAL. First, the optical constants are not provided at sufficient spectral resolution to mimic the relatively narrow $\nu_{2}\left(\mathrm{NO}_{3}^{-}\right)$mode of $\mathrm{AN}$ at $831 \mathrm{~cm}^{-1}$. Second, crystalline
AN is known to undergo various thermal phase transitions (Chellappa et al., 2012; Herrmann and Engel, 1997). Specifically, there are different thermodynamically stable phases at room temperature (phase IV) and upper tropospheric temperatures (phase V, stable below $255 \mathrm{~K}$ ), going along with marked changes of the habitus of the corresponding infrared spectra in certain wavenumber regimes, e.g., in the region between 1300 and $1500 \mathrm{~cm}^{-1}$ with contributions from the $v_{4}\left(\mathrm{NH}_{4}^{+}\right)$and $v_{3}\left(\mathrm{NO}_{3}^{-}\right)$modes (Fernandes et al., 1979; Koch et al., 1996; Shen et al., 1993; Théorêt and Sandorfy, 1964).

In this work, we have derived the first data set of complex refractive indices of crystalline AN at low temperature $(223 \mathrm{~K})$ with a sufficient spectral resolution $\left(0.5 \mathrm{~cm}^{-1}\right)$ to resolve the $v_{2}\left(\mathrm{NO}_{3}^{-}\right)$mode. The optical constants were deduced for the wavenumber range from 800 to $6000 \mathrm{~cm}^{-1}$, so they can be employed for the analysis of measurements in any appropriate region in the mid-infrared not too strongly affected by trace gas signatures. The complex refractive indices were iteratively derived from an infrared extinction spectrum of about $1 \mu \mathrm{m}$ sized, almost pure crystalline AN particles suspended in the AIDA chamber at $223 \mathrm{~K}$ (Sects. 2 and 3.1). A comprehensive sensitivity analysis shows the effect of measurement uncertainties and different assumptions regarding the shape of the AN particles (spherical or aspherical particle habits) on the optical constants deduced (Sect. 3.2). We demonstrate that this new data set is appropriate to accurately fit infrared limb observations of AN in the ATAL (Sect. 3.3).

\section{Methods}

\subsection{Experimental setup}

The experimental setup has been described in detail in our preceding articles (Höpfner et al., 2019; Wagner et al., 2020) and will only briefly be summarized here. Figure 1 shows a scheme of the AIDA aerosol and cloud chamber facility with the instrumentation employed in the present study (Möhler et al., 2003; Wagner et al., 2006b, 2009). The $84 \mathrm{~m}^{3}$ sized aerosol vessel, placed inside a temperature-controlled housing, was cooled to a temperature of $223 \mathrm{~K}$ to record the low-temperature infrared extinction spectrum of crystalline AN particles in their thermodynamic phase $\mathrm{V}$. The mean gas temperature was recorded by averaging the measurements of four vertically oriented thermocouple sensors mounted at different heights of the chamber with an uncertainty of $\pm 0.3 \mathrm{~K}$. The $\mathrm{RH}_{\mathrm{w}}$ (relative humidity with respect to supercooled water) was controlled to $22 \%$ by evaporating an equivalent amount of purified water (GenPure Pro UV ultrapure water system, Thermo Scientific) into the chamber. The resulting water vapor partial pressure, as measured by scanning the intensity of the rotational vibrational water vapor absorption line at $1.37 \mu \mathrm{m}$ with a tunable diode laser (TDL) (Fahey et al., 2014), was divided by the saturation water vapor pressure 
over liquid supercooled water to compute $\mathrm{RH}_{\mathrm{w}}$ (Murphy and Koop, 2005).

After the AIDA chamber was set to the desired temperature and relative humidity conditions, the injection of the mixed AN/AS aerosol particles was started. As described above, a small admixture of AS was needed to catalyze the crystallization of AN. We prepared an aqueous solution of $99.4 \mathrm{~mol} \%$ AN and $0.6 \mathrm{~mol} \%$ AS with an overall solute concentration of about $9 \mathrm{~g}$ per $100 \mathrm{~mL}$ by dissolving respective amounts of AN (99\%, VWR Chemicals) and AS (99.5\% Merck) in purified water. The aqueous solution was aerosolized with an ultrasonic nebulizer (GA 2400, SinapTec). The particle flow of the mixed AN/AS solution droplets was first dried to $\mathrm{RH}_{\mathrm{w}} \leq 3 \%$ with a set of silica gel diffusion dryers (Topas $\mathrm{GmbH}$ ) and then injected into the cooled AIDA chamber.

In our preceding studies, we have analyzed in detail the composition-dependent crystallization behavior of the mixed AN/AS solution droplets by varying the amount of AS and have found three different scenarios (Höpfner et al., 2019; Wagner et al., 2020). (i) Pure $100 \mathrm{~mol} \%$ AN solution droplets did not crystallize at all and could be maintained for at least $4 \mathrm{~h}$ in the supercooled liquid state at $223 \mathrm{~K}$. (ii) Mixed AN/AS solution droplets with an AS admixture of $\geq 10 \mathrm{~mol} \%$ already crystallized during the short transit time through the diffusion dryers and were immediately present as crystalline particles upon injection into the AIDA chamber. (iii) Mixed AN/AS solution droplets with smaller AS admixtures of $0.6 \mathrm{~mol} \%$ and $2.9 \mathrm{~mol} \%$ gradually crystallized at low temperature inside the AIDA chamber, with the crystallization rate depending on $\mathrm{RH}_{\mathrm{w}}$. We used two in situ techniques to monitor the ongoing crystallization of the AN/AS solution droplets in the AIDA chamber, namely, infrared extinction spectroscopy and laser light scattering with depolarization measurements. A Fourier transform infrared (FTIR) spectrometer (IFS66v, Bruker) was coupled to an internal multiple reflection cell to measure aerosol infrared extinction spectra over an optical path length of $166.8 \mathrm{~m}$ at wavenumbers between 800 and $6000 \mathrm{~cm}^{-1}$ with a resolution of $0.5 \mathrm{~cm}^{-1}$ (Wagner et al., 2006a). Five-hundred individual scans were averaged for each spectrum. The gradual crystallization of the AN/AS solution droplets was indicated by the continuous decrease of the liquid water extinction band at about $3500 \mathrm{~cm}^{-1}$. The near backscattering linear depolarization ratio, $\delta$, of the aerosol particles at a scattering angle of $178^{\circ}$ and a wavelength of $488 \mathrm{~nm}$ was measured by the light-scattering instrument SIMONE (Schnaiter et al., 2012). A continuous increase of $\delta$ over time was indicative of the formation of aspherical, crystalline AN particles and the concomitant loss of spherical, non-depolarizing solution droplets. The crystallization of the aerosol population was completed when a steady-state $\delta$ value was reached.

With regard to the crystallization experiment with the $99.4 \mathrm{~mol} \% \mathrm{AN}$ and $0.6 \mathrm{~mol} \% \mathrm{AS}$ solution droplets, the time series of $\delta$ indicated that the entire particle population had crystallized within a period of $1 \mathrm{~h}$ after aerosol injection (see Fig. 2a in Wagner et al., 2020). The infrared extinction spectrum of the almost pure, crystallized AN particles is shown in Fig. 2a of our article, including the AN vibrational assignment according to Fernandes et al. (1979). The minor fraction of AS likely crystallizes as one of the double salts 2AN - AS or 3AN - AS (Bothe and Beyer, 2007; Schlenker and Martin, 2005), but their specific extinction signatures, e.g., the additional sulfate mode at about $1100 \mathrm{~cm}^{-1}$ (Wagner et al., 2020), are barely visible. We can therefore treat the infrared measurement to a good approximation as a pure AN spectrum.

Concomitantly with their infrared spectrum, we measured the particle number size distributions by combining the size spectra from a scanning mobility particle sizer (SMPS, model $3071 \mathrm{~A}$, TSI, mobility diameter range $0.014-0.82 \mu \mathrm{m})$ and an aerodynamic particle spectrometer (APS, model 3321 , TSI, aerodynamic diameter range $0.523-19.81 \mu \mathrm{m}$ ). To convert the mobility diameter of the crystalline AN particles from the SMPS measurement into the equal-volume sphere diameter, $d_{\mathrm{p}}$, we adopted a dynamic shape factor, $\chi$, of 1.1 to account for the slightly aspherical particle habits of the AN crystals (Hinds, 1999). The same value for $\chi$ as well as the particle density of AN, $\rho(\mathrm{AN})=1.72 \mathrm{~g} \mathrm{~cm}^{-3}$, were chosen to transform the aerodynamic diameter from the APS measurement into $d_{\mathrm{p}}$ (Hinds, 1999; Kelly and McMurry, 1992). The resulting number size distribution as a function of $d_{\mathrm{p}}$ is shown in Fig. 2b. The dominant particle mode mostly falls into the measurement range of the APS instrument and is centered at $d_{\mathrm{p}}=0.98 \mu \mathrm{m}$. The integrated total number concentration of the AN particles, $N_{\text {aer }}$, is $985 \mathrm{~cm}^{-3}$ and is in good agreement with an independent measurement of $N_{\text {aer }}$ with a condensation particle counter (CPC, model 3010, TSI). The particle size measurement from Fig. $2 b$ and the infrared spectrum from Fig. 2a are the basic input parameters for the retrieval scheme of the optical constants (Sect. 2.2). Note that these two measurements were carried out in an overlapping time range and lasted about $6 \mathrm{~min}$. During this time, $N_{\text {aer }}$ varied by less than $0.5 \%$.

Another important parameter for the implementation of the retrieval approach is the shape of the crystalline AN particles. We have therefore recorded electron microscope images of filter-collected AN particles from the AIDA chamber (Fig. 2c). Note that these images were obtained from a different experiment with crystallized particles from $97.1 \mathrm{~mol} \%$ AN and $2.9 \mathrm{~mol} \%$ AS, but we do not expect that the slightly higher AS content significantly alters the particle shape. For particle sampling from the AIDA chamber, we have developed a method to collect aerosol particles in the cryopreserved state (Wagner et al., 2017). For that purpose, we used a vacuum cryo-transfer system (EM VCT500, Leica) to ensure an unbroken chain of cryogenic transfer steps from particle sampling to electron microscopic analysis (Fig. 1). This avoids the polymorphic phase change of the solid AN particles from phase $\mathrm{V}$ to IV, which might induce a change 


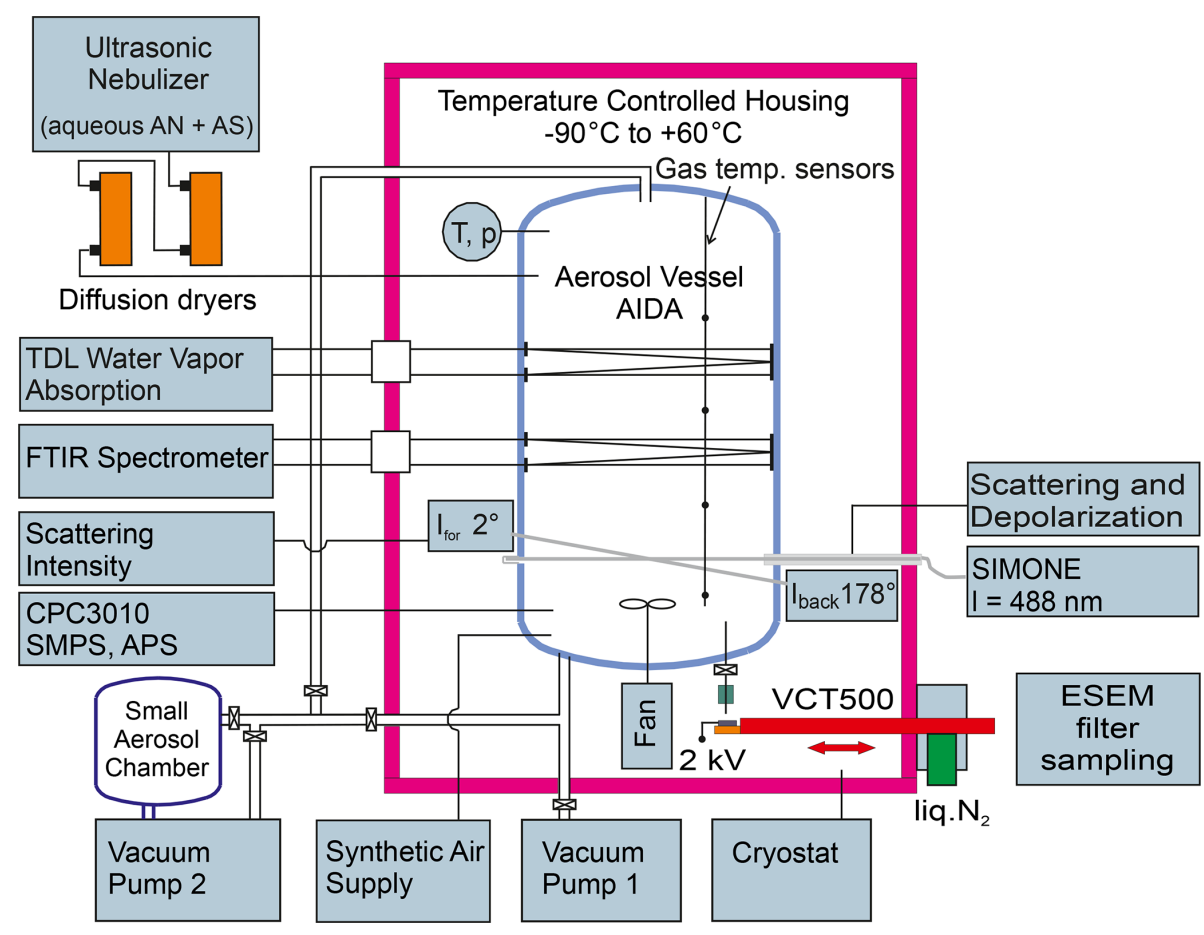

Figure 1. Scheme of the instrumentation of the AIDA aerosol and cloud chamber facility employed in the present study. The abbreviations are explained in Sect. 2.1.

of particle morphology. The cryo-transfer unit includes a liquid-nitrogen-cooled transfer shuttle with a silicon substrate mounted on a copper sample holder. For particle sampling, the Si substrate was introduced through a pneumatic air lock into a sampling chamber located inside the isolating containment of the AIDA chamber. The sampling of the AN particles was electrostatically assisted by directing the aerosol flow from the AIDA chamber through a polonium neutralizer (model 3077A, TSI) onto the sampling substrate connected to a high-voltage power supply set to $2 \mathrm{kV}$. After sampling, the substrate was retracted into the pre-cooled shuttle without exposing it to the ambient air. Thereafter, the shuttle was detached from the AIDA air lock and transferred under continuous supply of liquid nitrogen to the ESEM (environmental scanning electron microscope) laboratory, where it was introduced through the air lock into the microscope (Quattro S, FEI, Thermo Fisher Scientific). The sample imaging was conducted in the $\mathrm{N}_{2}$ atmosphere, thus avoiding sputtering of the particle surface normally required for high-resolution imaging in an SEM. The electron microscope images shown in Fig. 2c reveal that the crystalline AN particles are of rather compact shape with aspect ratios predominantly in the range from 0.80 to 1.25 . Similar morphologies have been reported for crystallized AS particles (Earle et al., 2006).

\subsection{Retrieval scheme for deriving the optical constants}

The retrieval scheme, as sketched in Fig. 3, follows standard procedures for the derivation of optical constants from aerosol infrared extinction spectra (Dohm and Niedziela, 2004; Earle et al., 2006; Norman et al., 1999; SegalRosenheimer et al., 2009; Signorell and Luckhaus, 2002; Zasetsky et al., 2005). Briefly, an initial guess for the wavenumber-dependent spectrum of the imaginary part of the complex refractive index, $k(\tilde{v})$, was derived by subtracting the scattering contribution from the measured infrared extinction spectrum (step 1). Using the subtractive Kramers-Kronig transformation (Ahrenkiel, 1971; Milham et al., 1981), we then computed the real part of the complex refractive index, $n(\tilde{v})$, for each wavenumber grid point of the measured spectrum (step 2). In its subtractive form, the Kramers-Kronig relation needs a so-called anchor point, which is a known value for the real index of refraction at some reference wavenumber, $n\left(\tilde{v}_{x}\right)$. As a reasonable estimate for the anchor point, we employed a value of $n=1.56$ at $4600 \mathrm{~cm}^{-1}$ from the tabulated room-temperature refractive indices by Jarzembski et al. (2003). The anchor point value was included as one of three parameters in our sensitivity analysis to investigate the variability of the retrieval results for the optical constants on the uncertainty ranges of the input parameters (Sect. 3.2). In this analysis, we also considered two other input values for $n\left(\tilde{v}_{x}\right)$, namely, 1.52 and 1.60 . 

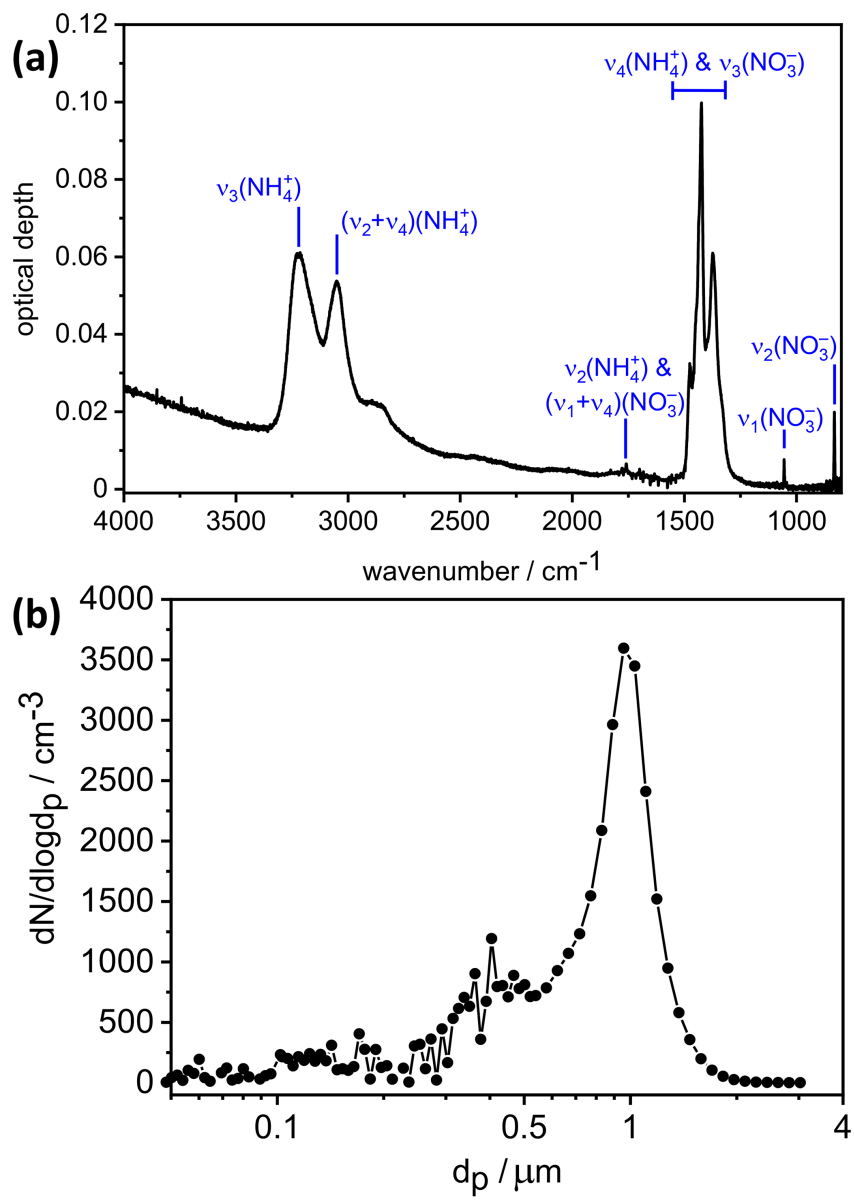

(c)

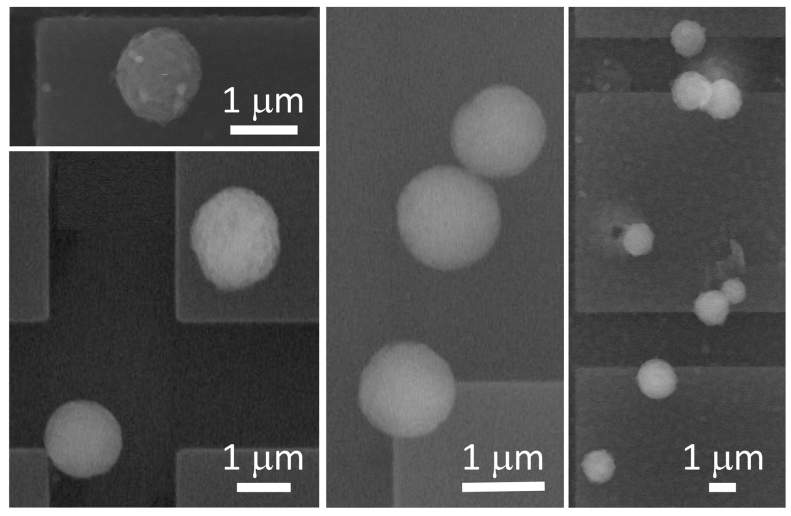

Figure 2. (a) Infrared extinction spectrum of crystalline AN particles recorded at $223 \mathrm{~K}$. The notation of the AN vibrational modes is according to Fernandes et al. (1979). (b) Concomitant number size distribution of the almost pure AN particles crystallized from solution droplets with $99.4 \mathrm{~mol} \% \mathrm{AN}$ and $0.6 \mathrm{~mol} \%$ AS. The data are shown as a function of the equal-volume sphere diameter, $d_{\mathrm{p}}$, as obtained by converting the mobility and aerodynamic size spectra from the SMPS and APS measurements with $\rho$ (AN) $=1.72 \mathrm{~g} \mathrm{~cm}^{-3}$ and $\chi=1.1$. (c) Exemplary electron microscope images of filtersampled, continuously cooled AN crystals from a crystallization experiment with $97.1 \mathrm{~mol} \% \mathrm{AN}$ and $2.9 \mathrm{~mol} \% \mathrm{AS}$.

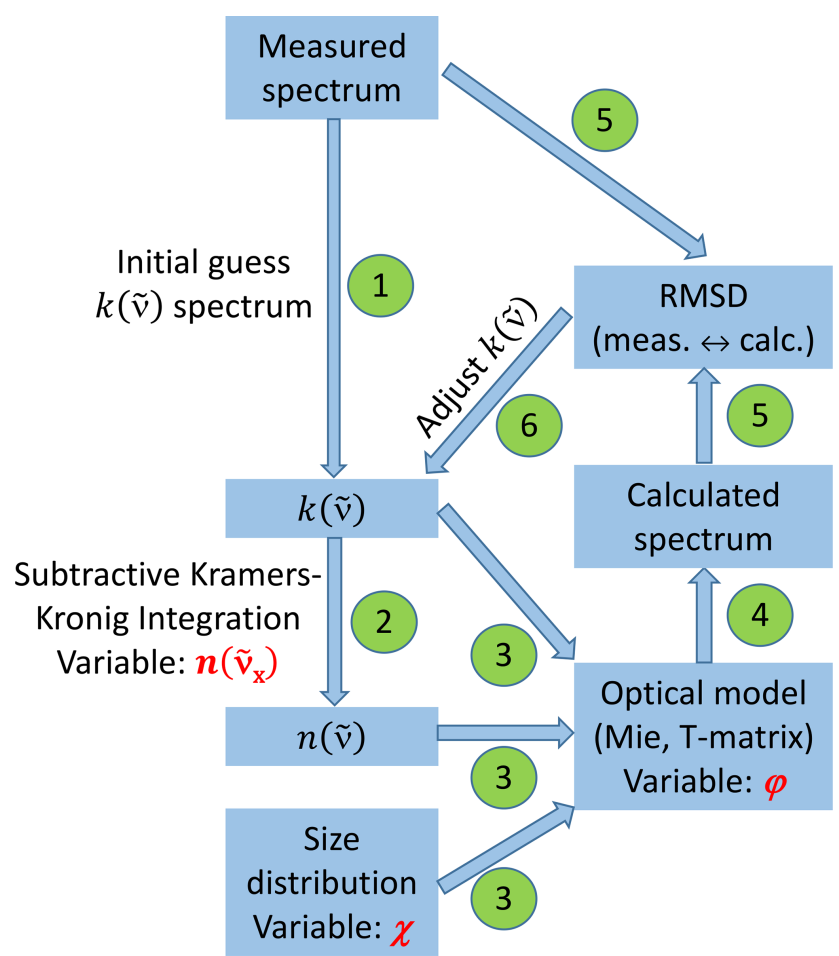

Figure 3. Flowchart of the retrieval scheme to deduce the optical constants of the crystalline AN particles. All abbreviations, symbols, and steps in the procedure (numbered green circles) are explained in Sect. 2.2.

In step 3 of the retrieval scheme, the $n(\tilde{v})$ and $k(\tilde{v})$ spectra as well as the size distribution of the AN particles were fed into the optical model to compute the extinction spectrum. The size distribution measurement involved another sensitivity parameter, namely, the dynamic shape factor $\chi$ (Hinds, 1999). As explained in Sect. 2.1, this parameter was needed to account for the effect of shape on particle motion when converting the measured mobility and aerodynamic diameters of the crystalline AN particles into equal-volume sphere diameters as input for the optical model (Fig. 2b). Our best estimate for $\chi$ was a value of 1.1, as representative for slightly aspherical particle habits (Hinds, 1999). For $\chi=1.1$, we obtained a median particle diameter of $0.98 \mu \mathrm{m}$ and a total aerosol volume concentration, $V_{\text {aer }}$, of $410 \mu \mathrm{m}^{3} \mathrm{~cm}^{-3}$. In our sensitivity analysis (Sect. 3.2), we have repeated the retrieval procedure of the optical constants with two other $\chi$ values, namely, 1.05 and 1.15 , in order to test the impact of the uncertainty of $\chi$ on the deduced refractive indices. For $\chi=1.05$, the median diameter of the dominant particle mode is shifted to $0.96 \mu \mathrm{m}$, decreasing $V_{\text {aer }}$ by about $7 \%$ to $380 \mu \mathrm{m}^{3} \mathrm{~cm}^{-3}$, whereas for $\chi=1.15$, it is shifted to $1.00 \mu \mathrm{m}$, increasing $V_{\text {aer }}$ by about $7 \%$ to $440 \mu \mathrm{m}^{3} \mathrm{~cm}^{-3}$.

The third sensitivity parameter was the particle aspect ratio, $\varphi$, employed in the optical model. We first derived the optical constants using Mie theory under the assumption of 
spherical particles $(\varphi=1)$. In the sensitivity analysis, we additionally used the T-matrix code to model the AN particles as randomly oriented spheroids with six different aspect ratios between $\varphi=0.5$ and 2.0 (Mishchenko and Travis, 1998). After the computation of the extinction spectrum (step 4), we calculated the root-mean-square deviation (RMSD) between calculated and measured infrared spectrum (step 5), and we finished the loop by iteratively adjusting the initial guess $k(\tilde{v})$ spectrum to minimize the RMSD (step 6). The computational details of the retrieval scheme are described in Appendix A. Figure A1 therein shows the good agreement between calculated and measured infrared spectrum after the minimization procedure.

\section{Results and discussion}

\subsection{The new low-temperature data set of optical constants for crystalline AN}

Figure 4 shows our newly derived, low-temperature complex refractive index data set for crystalline $\mathrm{AN}$, as obtained when employing the parameter values $n\left(\tilde{v}_{x}\right)=1.56$, $\chi=1.1$, and $\varphi=1$ in the retrieval scheme (black line). In comparison with the room-temperature data from Jarzembski et al. (2003) (red line), the general magnitude of the imaginary indices in the various absorption regimes is similar, with maximum $k$ values of about $0.5,2$, and 1 in the wavenumber regimes $2800-3500,1250-1500$, and $820-840 \mathrm{~cm}^{-1}$, respectively. The low-temperature $k(\tilde{v})$ spectrum reveals more fine structure in the $2800-3500$ and $1250-1500 \mathrm{~cm}^{-1}$ absorption regions compared to the room-temperature data set. Very similar temperature-dependent spectral changes have been observed between the infrared spectra of AN films recorded at 270 and $90 \mathrm{~K}$ (Koch et al., 1996; see spectra B and C in their Fig. 4) and were attributed to the temperature-induced polymorphic phase change of AN between phase IV and phase $\mathrm{V}$. The peak positions of the infrared absorption bands in our low-temperature $k(\tilde{v})$ spectrum, that is, $3235 \mathrm{~cm}^{-1}$ for $v_{3}\left(\mathrm{NH}_{4}^{+}\right), 3062 \mathrm{~cm}^{-1}$ for $\left(v_{2}+v_{4}\right)\left(\mathrm{NH}_{4}^{+}\right), 1760 \mathrm{~cm}^{-1}$ for $v_{2}\left(\mathrm{NH}_{4}^{+}\right), 1055 \mathrm{~cm}^{-1}$ for $v_{1}\left(\mathrm{NO}_{3}^{-}\right)$, and $831 \mathrm{~cm}^{-1}$ for $v_{2}\left(\mathrm{NO}_{3}^{-}\right)$, are in good agreement with the tabulated values for ammonium nitrate films probed at $90 \mathrm{~K}$ (Koch et al., 1996). In contrast, we observed a different spectral pattern in the $1250-1500 \mathrm{~cm}^{-1}$ regime, with band maxima centered at 1356,1418 , and $1476 \mathrm{~cm}^{-1}$, whereas peak positions at $1320,1367,1397,1462$, and $1492 \mathrm{~cm}^{-1}$ were reported by Koch et al. (1996). They emphasized that this particular wavenumber region was very sensitive to the procedure by which the AN films were deposited, arguing that the $v_{4}\left(\mathrm{NH}_{4}^{+}\right)$and $v_{3}\left(\mathrm{NO}_{3}^{-}\right)$modes are prone to site-sensitive coupling due to their similar frequencies. Regarding our $k(\tilde{v})$ spectrum, we will show in Sect. 3.2 that the $1250-1500 \mathrm{~cm}^{-1}$ wavenumber regime is also particularly sensitive to the variation of the parameter values $n\left(\tilde{v}_{x}\right), \chi$, and $\varphi$, which con-

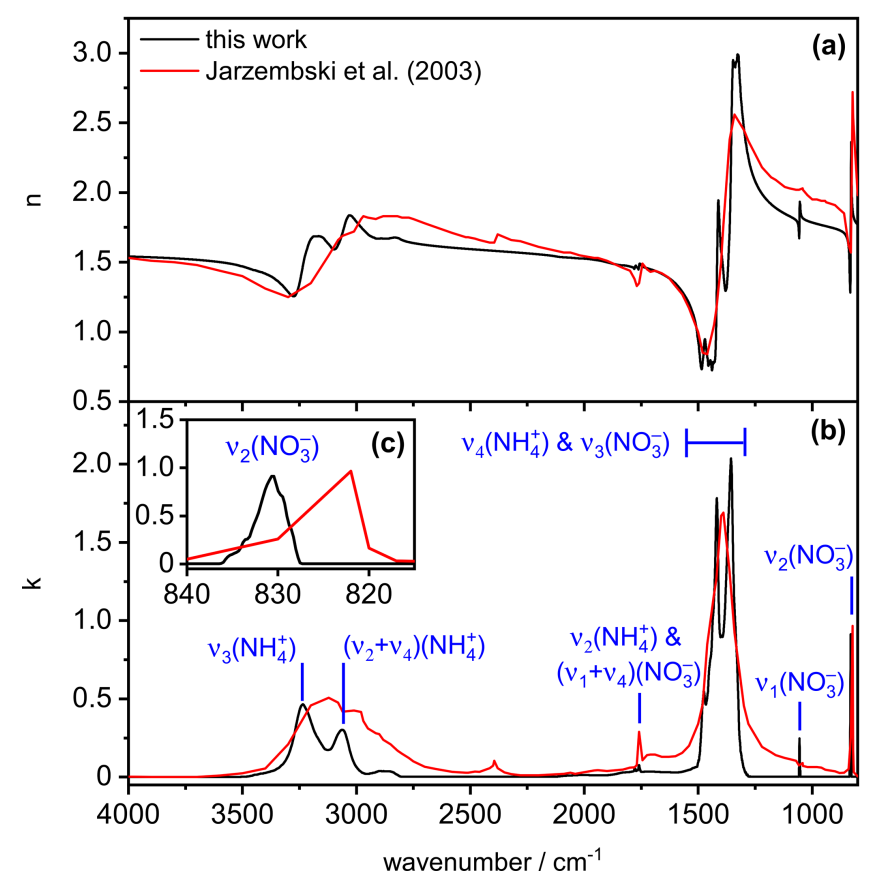

Figure 4. Real (a) and imaginary (b) parts of the complex refractive for solid AN at $223 \mathrm{~K}$ derived from this work (black lines) in comparison with room-temperature data from Jarzembski et al. (2003) (red lines). The insert (c) shows an expanded view of the $k$ spectrum in the regime of the $v_{2}\left(\mathrm{NO}_{3}^{-}\right)$mode.

tributes to the observed frequency and intensity shifts with respect to the infrared spectrum of the AN film in that region. With regard to the $v_{2}\left(\mathrm{NO}_{3}^{-}\right)$mode of $\mathrm{AN}$, Koch et al. (1996) did not observe any frequency shift upon cooling from 270 to $90 \mathrm{~K}$. Also, room-temperature infrared measurements of solid AN particles pointed to the same band position at $831 \mathrm{~cm}^{-1}$ as in our low-temperature spectrum (Schlenker and Martin, 2005). The apparent shift of this band in the $k$ spectrum reported by Jarzembski et al. (2003) (Fig. 4c) might therefore be related to the insufficient spectral resolution of the underlying infrared spectrum used for the retrieval of the optical constants.

\subsection{Sensitivity analysis}

An overview about our sensitivity analysis regarding the effect of different values for the parameters $n\left(\tilde{v}_{x}\right), \chi$, and $\varphi$ on the retrieved $k(\tilde{v})$ spectrum of the AN particles is shown in Fig. 5. In the first part (panels a-c), we varied $n\left(\tilde{v}_{x}\right)$ between 1.52 and 1.60 while keeping $\chi$ and $\varphi$ constant at 1.1 and 1 , respectively. The associated changes in $k(\tilde{v})$ were small; most notably, an increasing value for the real refractive index at the anchor point of $4600 \mathrm{~cm}^{-1}$ led to slightly decreasing intensities of the $k(\tilde{v})$ spectrum in the $\mathrm{N}-\mathrm{H}$ stretching mode regime between 2800 and $3500 \mathrm{~cm}^{-1}$, whereas the $k$ values of the $v_{2}\left(\mathrm{NO}_{3}^{-}\right)$mode at $831 \mathrm{~cm}^{-1}$ almost remained unaffected. Different values for $\chi$ (panels $\mathrm{d}-\mathrm{f}$ ) immediately 

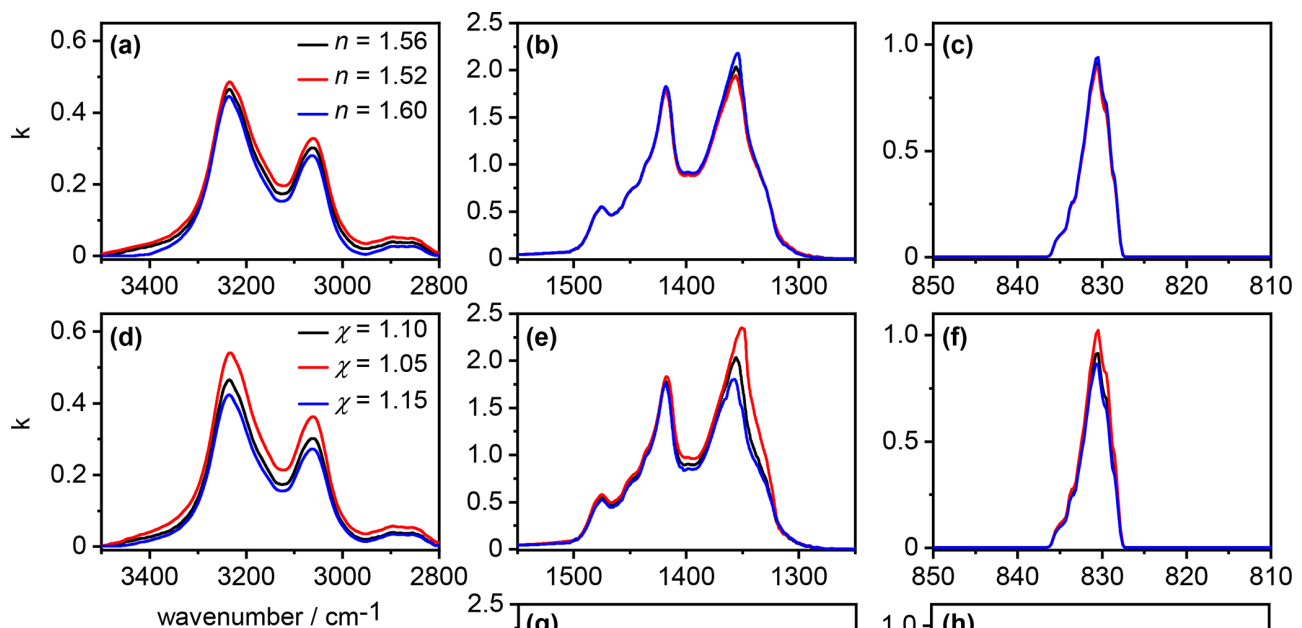

$$
\begin{aligned}
& -\varphi=1 \\
& -\varphi=1 / 2-\varphi=2 / 1 \\
& -\varphi=2 / 3-\varphi=3 / 2 \\
& -\varphi=4 / 5-\varphi=5 / 4
\end{aligned}
$$
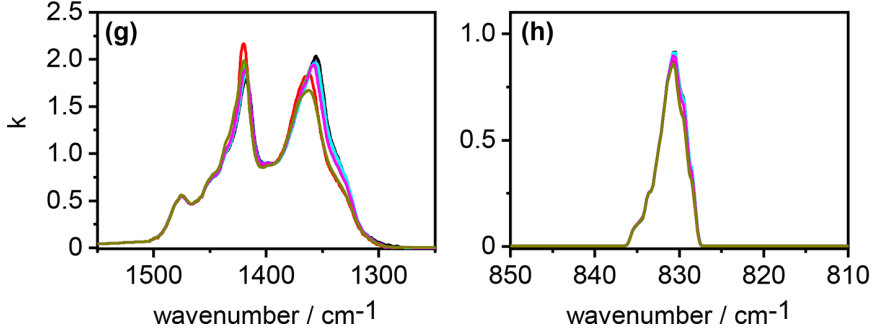

Figure 5. Sensitivity of the retrieved $k(\tilde{v})$ spectrum on the parameters $n\left(\tilde{v}_{x}\right), \chi$, and $\varphi$ in different wavenumber regimes. (a-c) Variation of $n\left(\tilde{v}_{x}\right)$ with $\chi=1.1$ and $\varphi=1$. (d-f) Variation of $\chi$ with $n\left(\tilde{v}_{x}\right)=1.56$ and $\varphi=1$. $(\mathbf{g}, \mathbf{h})$ Variation of $\varphi$ with $n\left(\tilde{v}_{x}\right)=1.56$ and $\chi=1.1$.

affected the size distribution and thereby the overall volume concentration of the AN particles, $V_{\text {aer }}$, with lower values for $\chi$ giving rise to lower values for $V_{\text {aer }}$ (see Sect. 2.2). Within the approximation that particle absorption is primarily governed by the magnitude of the imaginary index $k$, a lower value for $\chi$, that is, $V_{\text {aer }}$, must be balanced by higher $k$ values in the retrieved $k(\tilde{v})$ spectrum. Such behavior was indeed observed in the wavenumber regimes of the moderately intense absorption bands of AN between 2800 and $3500 \mathrm{~cm}^{-1}$ as well as 810 and $850 \mathrm{~cm}^{-1}$. In particular, the $k$ values were regularly increased or decreased over the whole wavenumber region of the absorption bands when $\chi$ was decreased or increased, respectively.

The above approximation breaks down in the regime of the very intense vibrational modes of AN between 1200 and $1500 \mathrm{~cm}^{-1}$. With high values for the imaginary index $(k>1)$, going along with high-amplitude anomalous dispersion signals in the $n$ spectrum (Fig. 4), the resonance condition for inducing so-called Fröhlich or surface modes can be fulfilled, meaning that $n$ approaches zero and $k$ adopts a value of $\sqrt{2}$ (Bohren and Huffman, 1983; Clapp and Miller, 1993; Leisner and Wagner, 2011). In such a case, there will be an enhanced cross section in the absorption spectrum of small spherical particles, and the spectral habitus of an absorption band (including, for example, band intensity and peak position) can strongly differ from the $k(\tilde{v})$ spectrum. Regarding our sensitivity analysis, this meant that the variation of $\chi$, that is, $V_{\text {aer }}$, did not lead to a regular, predictable change in the retrieved $k(\tilde{v})$ spectrum as in the other wavenumber regimes with the less intense absorption bands. The variation of $\chi$ only affected a certain wavenumber region between 1320 and $1370 \mathrm{~cm}^{-1}$ in the retrieval result for $k(\tilde{v})$ (Fig. 5e). In Appendix B and the associated Figs. B1 and B2, we provide an extended description of the peculiar signature of the AN infrared spectrum in the $1200-1500 \mathrm{~cm}^{-1}$ regime.

Frequency and intensity of the surface modes are strongly dependent on the particle shape (Bohren and Huffman, 1983; Clapp and Miller, 1993). We therefore obtained pronounced, shape-dependent variations in the retrieval results for the $k(\tilde{v})$ spectrum in the $1200-1500 \mathrm{~cm}^{-1}$ regime when modifying the aspect ratio of the crystalline AN particles (Fig. $5 \mathrm{~g}$ ). For spherical particles with $\varphi=1$, the two most intense maxima in the retrieved $k(\tilde{v})$ spectrum were at 1418 and $1356 \mathrm{~cm}^{-1}$, with the latter having the higher intensity. An increasing degree of asphericity inverted the intensities of these two maxima, with the $1418 \mathrm{~cm}^{-1}$ band slightly shifted to higher wavenumbers and becoming the more intense one and the $1356 \mathrm{~cm}^{-1}$ band, also slightly shifted to higher wavenumbers, becoming the less intense one. These shapedependent absorption signatures induce a further degree of complexity to the infrared spectrum of AN in the 1200 $1500 \mathrm{~cm}^{-1}$ wavenumber regime, in addition to the variability already highlighted by Koch et al. (1996) regarding the thin-film AN spectra. In contrast, the shape-dependent variations of the retrieved $k(\tilde{v})$ spectrum in the regime of the $v_{2}\left(\mathrm{NO}_{3}^{-}\right)$mode were small (Fig. $5 \mathrm{~h}$ ). The maximum value 
for $k$ at $831 \mathrm{~cm}^{-1}$ varied by at most $6 \%$ between the retrieval results for the various aspect ratios, with a trend of decreasing maximum value with increasing degree of asphericity. The shape-related spectral changes in the $2800-3500 \mathrm{~cm}^{-1}$ regime of the $k(\tilde{v})$ spectrum were insignificant and are therefore not shown.

\subsection{Application of the new refractive index data set}

We consider the refractive index data set derived for $n\left(\tilde{v}_{x}\right)=$ 1.56, $\chi=1.1$, and $\varphi=1$ as our current best estimate for the optical constants of crystalline AN at $223 \mathrm{~K}$ (Fig. 4). However, we also provide the data sets retrieved for all sensitivity studies described in Sect. 3.2 and strongly encourage any modelers who apply our data to take into account these uncertainties of $n$ and $k$ in their own spectral analyses. Regarding the influence of particle asphericity investigated by the T-matrix calculations, we have considered aspect ratios partly exceeding the actual particle eccentricities as revealed by the electron microscope images (Fig. 2c) to ensure that we derived a valid upper estimate for the uncertainty of $n$ and $k$ related to the shape dependency of the infrared extinction signatures of AN. As each individual $n$ and $k$ data set relies on an idealized representation for the shape of the AN particles (either spherical or spheroidal with a fixed aspect ratio), modelers might also consider using a shape-averaged $n$ and $k$ data set in their analyses (Mishchenko et al., 1997).

We used the new refractive index data set of AN to reanalyze infrared limb observations of the ATAL with the airborne GLORIA (Gimballed Limb Observer for Radiance Imaging of the Atmosphere) instrument during the StratoClim research flight on 31 July 2017 (Fig. 6a). The AN mass concentrations derived with the $n\left(\tilde{v}_{x}\right)=1.56, \chi=1.1$, and $\varphi=1$ data set agree within $0.01 \pm 0.06 \mu \mathrm{g} \mathrm{m}^{-3}(3 \sigma)$ with those previously estimated using the mass-specific absorption coefficients (see Fig. 3b in Höpfner et al., 2019). Maximum deviations of about $\pm 0.04 \mu \mathrm{g} \mathrm{m}^{-3}$ for the retrieved $\mathrm{AN}$ mass concentrations are obtained in the sensitivity analysis when considering the uncertainties of the $n$ and $k$ values. The measured infrared spectrum of the $v_{2}\left(\mathrm{NO}_{3}^{-}\right)$mode of the AN particles (blue line in Fig. 6b), showing the difference of mean GLORIA spectra recorded in periods of high and low AN mass concentrations, is accurately reproduced in the spectral fit with the new optical constants (orange line). Apart from the $v_{2}\left(\mathrm{NO}_{3}^{-}\right)$mode, our new data set of refractive indices also opens the possibility to exploit bands in other spectral regimes for the detection and quantification of $\mathrm{AN}$ in remote sensing observations of the atmosphere.
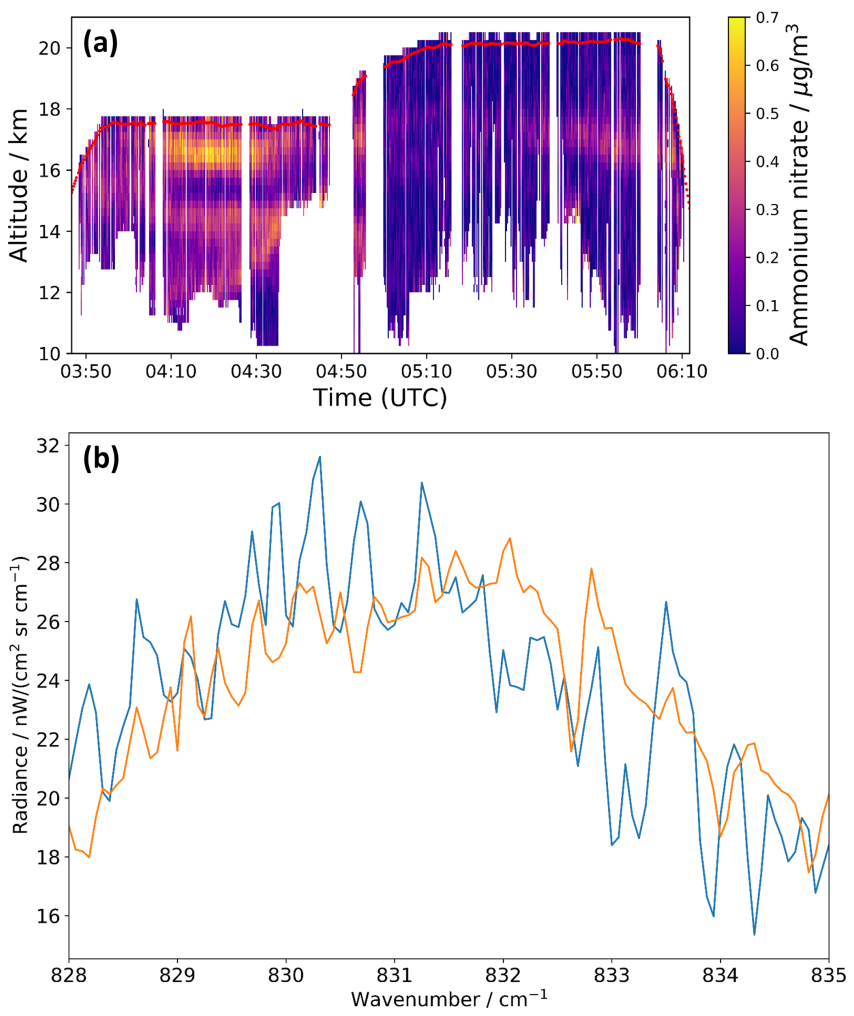

Figure 6. (a) AN mass concentrations retrieved from GLORIA measurements during the StratoClim research flight on 31 July 2017 using the $n\left(\tilde{v}_{x}\right)=1.56, \chi=1.1$, and $\varphi=1$ refractive index data set (see Fig. 3b in Höpfner et al., 2019, as a comparison). Red line: aircraft altitude. (b) Difference of mean GLORIA spectra between 04:15-04:21 and 04:35-04:43 UTC at 16.5-16.75 km altitude (blue) and best spectral fit with the AN optical constants (orange) in the range of the $v_{2}\left(\mathrm{NO}_{3}^{-}\right)$mode. 


\section{Appendix A: Computational details of the retrieval scheme}

Here, we describe the computational details of the individual steps in the retrieval scheme for deriving the infrared complex refractive indices of AN (Fig. 3). The wavenumber-dependent complex refractive index, $N(\tilde{v})$, is given as $N(\tilde{v})=n(\tilde{v})+i k(\tilde{v})$, with the real $(n)$ and imaginary $(k)$ parts called the optical constants. Our retrieval approach takes advantage of the Kramers-Kronig relation (Bohren and Huffman, 1983), by which the real refractive index can be computed at any given wavenumber $\tilde{v}_{k}$ from the full wavenumber spectrum of $k(\tilde{v})$ (Eq. A1).

$n\left(\tilde{v}_{k}\right)-1=\frac{2}{\pi} P \int_{0}^{\infty} \frac{k(\tilde{v}) \tilde{v}}{\tilde{v}^{2}-\tilde{v}_{k}^{2}} \mathrm{~d} \tilde{v}$

In step 1 of our retrieval approach, where we derived an initial guess for the optical constants of AN from the measured infrared extinction spectrum, we made use of a different form of the Kramers-Kronig relation, linking the real and imaginary parts of the composite function $f=$ $\left(N^{2}(\tilde{v})-1\right) /\left(N^{2}(\tilde{v})+2\right)$ (Rouleau and Martin, 1991).

$\operatorname{Re}\{f\}\left(\tilde{v}_{k}\right)=\frac{2}{\pi} P \int_{0}^{\infty} \frac{\operatorname{Im}\{f\}(\tilde{v}) \tilde{v}}{\tilde{v}^{2}-\tilde{v}_{k}^{2}} \mathrm{~d} \tilde{v}$

For the initial estimate of $k(\tilde{v})$, we analyzed the extinction spectrum of the $1 \mu \mathrm{m}$ sized AN crystals in the framework of Rayleigh theory (Bohren and Huffman, 1983). The scattering contribution to extinction was subtracted from the measurement by assuming its intensity to be proportional to $\tilde{v}^{4}$ (Norman et al., 1999). In the Rayleigh limit, the so-derived absorption spectrum is directly proportional to the total aerosol volume concentration, $V_{\text {aer }}$, and to the imaginary part of the composite function $f, \operatorname{Im}\{f\}$ (Ossenkopf et al., 1992). With $V_{\text {aer }}$ given by the SMPS and APS size distribution measurements as discussed in Sect. 2.1, we could thus derive the full wavenumber spectrum of $\operatorname{Im}\{f\}$ from the estimated absorption spectrum, perform the Kramers-Kronig integration in Eq. (A2) to obtain the spectrum of $\operatorname{Re}\{f\}$, and calculate the initial guess for $k(\tilde{v})$ from $\operatorname{Re}\{f\}$ and $\operatorname{Im}\{f\}$ (Leisner and Wagner, 2011; Segal-Rosenheimer et al., 2009).

The initial guess $k(\tilde{v})$ spectrum had to be iteratively adjusted using Mie theory or the T-matrix method, because the generic requirement for the validity of the Rayleigh approximation, that is, the AN particles have to be very small compared to any of the wavelengths (Bohren and Huffman, 1983), was not fulfilled for the entire measurement range in the mid-infrared. The Kramers-Kronig integration in its form of Eq. (A2) was therefore only applied once in step 1 of the retrieval scheme. In step 2, which was part of the loop for the iterative adjustment of $k(\tilde{v})$, we employed the direct relation between $n(\tilde{v})$ and $k(\tilde{v})$, implementing Eq. (A1) in the version of the subtractive Kramers-Kronig transformation to minimize the effect of truncation errors due to the unknown behavior of $k(\tilde{v})$ beyond the experimentally accessible wavenumber range (Ahrenkiel, 1971; Milham et al., 1981; Segal-Rosenheimer and Linker, 2009).

$n\left(\tilde{v}_{k}\right)=n\left(\tilde{v}_{x}\right)+\frac{2\left(\tilde{v}_{k}^{2}-\tilde{v}_{x}^{2}\right)}{\pi} P \int_{0}^{\infty} \frac{k(\tilde{v}) \tilde{v}}{\left(\tilde{v}^{2}-\tilde{v}_{k}^{2}\right)\left(\tilde{v}^{2}-\tilde{v}_{x}^{2}\right)} \mathrm{d} \tilde{v}$

As described in Sect. 2.2, the anchor point value, $n\left(\tilde{v}_{x}\right)$, was set to 1.56 at $4600 \mathrm{~cm}^{-1}$. Two other values for $n\left(\tilde{v}_{x}\right)$, namely, 1.52 and 1.60 , were adopted in our sensitivity analysis (Sect. 3.2). Prior to performing the KramersKronig integration, we extended the $k(\tilde{v})$ spectrum below the $800 \mathrm{~cm}^{-1}$ cutoff of our infrared measurements with the room-temperature $k$ values reported by Jarzembski et al. (2003). These data are available down to $500 \mathrm{~cm}^{-1}$ but just show one further, spectrally narrow absorption band at $717 \mathrm{~cm}^{-1}$ with a maximum $k$ value of about 0.1 . To fully capture this mode, it was sufficient to consider the range from 800 to $690 \mathrm{~cm}^{-1}$ for the extension. We interpolated the Jarzembski et al. (2003) $k$ data in this range to the resolution of our measurements and added them to the $k(\tilde{v})$ spectrum below $800 \mathrm{~cm}^{-1}$ before the Kramers-Kronig integration. The integral was computed with Maclaurin's formula method (Ohta and Ishida, 1988).

For the Mie calculations, modeling the crystalline AN particles as spheres with an aspect ratio, $\varphi$, of one, we extended the Mie code provided by Bohren and Huffman (1983) to average the computed extinction cross sections over the measured number distribution of particle sizes. Due to their computational efficiency, the Mie computations were explicitly included in each iteration, meaning that for each new adjustment of the $k(\tilde{v})$ and $n(\tilde{v})$ spectra, a new Mie calculation of the extinction spectrum was executed. In order to investigate the effect of particle shape on the retrieval results for the optical constants, we also modeled the AN particles as randomly oriented spheroids, considering both oblate $(\varphi>1)$ and prolate $(\varphi<1)$ particle shapes. To compute the extinction cross sections, we used the extended precision T-matrix code for randomly oriented particles by Mishchenko and Travis (1998), choosing six different aspect ratios, namely, $\varphi=1 / 2, \varphi=2 / 3, \varphi=4 / 5, \varphi=5 / 4, \varphi=3 / 2$, and $\varphi=2$. Here, the computational burden would have been too high to perform a complete T-matrix computation of the sizeaveraged extinction spectrum of the AN particles each time the $k(\tilde{v})$ and $n(\tilde{v})$ spectra were newly adjusted during the optimization procedure. We therefore computed a priori for each aspect ratio an extinction cross section database on a three-dimensional parameter space, which served as a lookup table in the retrieval procedure. Specifically, the extinction cross sections were computed for

- 27 equal-volume sphere size parameters $x_{\mathrm{p}}\left(x_{\mathrm{p}}=\right.$ $\left.\pi d_{\mathrm{p}} / \lambda\right)$ between 0.005 and $5(0.005,0.01,0.03,0.05$, $0.1,0.2-4.0$ with $\Delta x_{\mathrm{p}}=0.2,4.5$, and 5), 
- 30 values for the real refractive index $n$ between 0.4 and 3.3 with $\Delta n=0.1$, and

- 29 values for the imaginary refractive index $k$ between 0.0001 and $2.5(0.0001,0.025,0.05,0.075,0.1-2.5$ with $\Delta k=0.1)$,

summing up to 23490 individual calculations for each aspect ratio. In the iterative loop of the retrieval scheme, the Tmatrix computed extinction spectrum for a new adjustment of $k(\tilde{v})$ and $n(\tilde{v})$ was then simply obtained by spline interpolation from the pre-computed extinction cross section database. We have validated the accuracy of the interpolation scheme with the denoted number of grid points in the $\left(x_{\mathrm{p}}, n\right.$, $k$ ) space by the comparison between directly computed and interpolated extinction cross sections.

To minimize the root-mean-square deviation between measured and calculated extinction spectrum, we used the downhill simplex algorithm as the optimization technique in the iterative adjustment of the $k(\tilde{v})$ spectrum (Press et al., 1992). The measured spectrum is provided in a digital resolution of about $0.24 \mathrm{~cm}^{-1}$, resulting from an approximately doubled size of the original interferogram due to zerofilling with a factor of 2 (Aroui et al., 2012). Overall, this amounts to 21572 wavenumber grid points for the $k(\tilde{v})$ spectrum in the wavenumber range between 800 and $6000 \mathrm{~cm}^{-1}$. The $k(\tilde{v})$ spectrum of AN features regimes with vastly varying types of absorption signatures, including, for example, completely non-absorbing regions, regimes of spectrally broad but weak absorption, and regimes with strong absorption bands, either spectrally broad or narrow. In the retrieval scheme, the various spectral regimes were treated differently and not all wavenumber grid points were included as optimization parameters.

- For wavenumber region $800-1250 \mathrm{~cm}^{-1}$, this regime includes the spectrally narrow $v_{2}\left(\mathrm{NO}_{3}^{-}\right)$and $v_{1}\left(\mathrm{NO}_{3}^{-}\right)$ modes at 831 and $1055 \mathrm{~cm}^{-1}$. Apart from these two pronounced bands, the absorption is very low. We therefore optimized the $k(\tilde{v})$ values in the regimes 826-836 and $1050-1060 \mathrm{~cm}^{-1}$ with the full spectral resolution. All other $k$ values were set to a small, constant background value of 0.002 in order to not transfer the noise from the baseline in the experimental spectrum to the $k(\tilde{v})$ spectrum.

- For wavenumber region $1250-1500 \mathrm{~cm}^{-1}$, this regime comprises the intense, spectrally broad absorption bands due to the $v_{4}\left(\mathrm{NH}_{4}^{+}\right)$and $v_{3}\left(\mathrm{NO}_{3}^{-}\right)$modes. All $k(\tilde{v})$ values were included in the optimization, but we applied a weak smoothing function prior to the Kramers-Kronig transformation to improve the convergence behavior of the optimization algorithm (Savitzky-Golay smoothing filter, quadratic polynomial fit with five data points in the moving window) (Press et al., 1992).
- For wavenumber region $1500-2800 \mathrm{~cm}^{-1}$, this regime includes two very weak but spectrally narrow absorption signatures between about 1750 and $1785 \mathrm{~cm}^{-1}$, presumably due to the $v_{2}\left(\mathrm{NH}_{4}^{+}\right)$and $\left(v_{1}+v_{4}\right)\left(\mathrm{NO}_{3}^{-}\right)$ modes (Fernandes et al., 1979; Koch et al., 1996). In that part, we optimized all $k(\tilde{v})$ values without any smoothing filter. Outside the $1750-1785 \mathrm{~cm}^{-1}$ region, the residual absorption is spectrally broad and very small, so we either used a strong smoothing filter or set the $k$ values to a small, constant background value of 0.002. Note that Fernandes et al. (1979) have assigned further, very weak infrared bands of AN, mostly combination modes, in the region between 2000 and $2800 \mathrm{~cm}^{-1}$. We were not able to detect these signatures in our measured spectrum; hence, these bands are not represented in our retrieved $k(\tilde{v})$ spectrum.

- For wavenumber region $2800-3500 \mathrm{~cm}^{-1}$, this regime comprises the intense $\mathrm{N}-\mathrm{H}$ stretching modes and was treated in the same way as the $1250-1500 \mathrm{~cm}^{-1}$ wavenumber region.

- For wavenumber region $3500-6000 \mathrm{~cm}^{-1}$, in this nonabsorbing regime, all $k(\tilde{v})$ values were set to zero.

A comparison between the measured (black lines) and the computed (red lines) infrared extinction spectrum of crystalline AN particles in five different wavenumber regimes after convergence of the optimization algorithm is shown in Fig. A1. The above description specifically relates to the retrievals performed with Mie theory. Regarding the Tmatrix computations, the analysis of the extinction cross section database showed that the wavenumber region above $1500 \mathrm{~cm}^{-1}$ was only prone to minor shape-related changes for the considered range of aspect ratios. Therefore, the analysis of the shape-dependent variations in the retrieval results for the optical constants of AN was confined to the 800 $1500 \mathrm{~cm}^{-1}$ regime (see Fig. $5 \mathrm{~g}$ and h).

\section{Appendix B: Analysis of the infrared extinction signature of the $\mathrm{AN}$ particles between 1200 and $1500 \mathrm{~cm}^{-1}$}

In order to better understand the signature of the infrared extinction spectrum of the crystalline AN particles in the $1200-1500 \mathrm{~cm}^{-1}$ wavenumber regime, we show in Fig. B1 the comparison between the measured extinction spectrum (panel a) and the retrieved optical constants for $n\left(\tilde{v}_{x}\right)=$ 1.56, $\chi=1.1$, and $\varphi=1$ (panel b). It is obvious that the spectral signature of the measured extinction bands of the AN particles is clearly different from that of the underlying $k(\tilde{v})$ spectrum, that is, different from a bulk absorption spectrum of AN whose intensity would be proportional to $k(\tilde{v}) \cdot \tilde{v}$ (Bohren and Huffman, 1983). The two most intense maxima in the $k(\tilde{v})$ spectrum at 1418 and $1356 \mathrm{~cm}^{-1}$ (dashed 

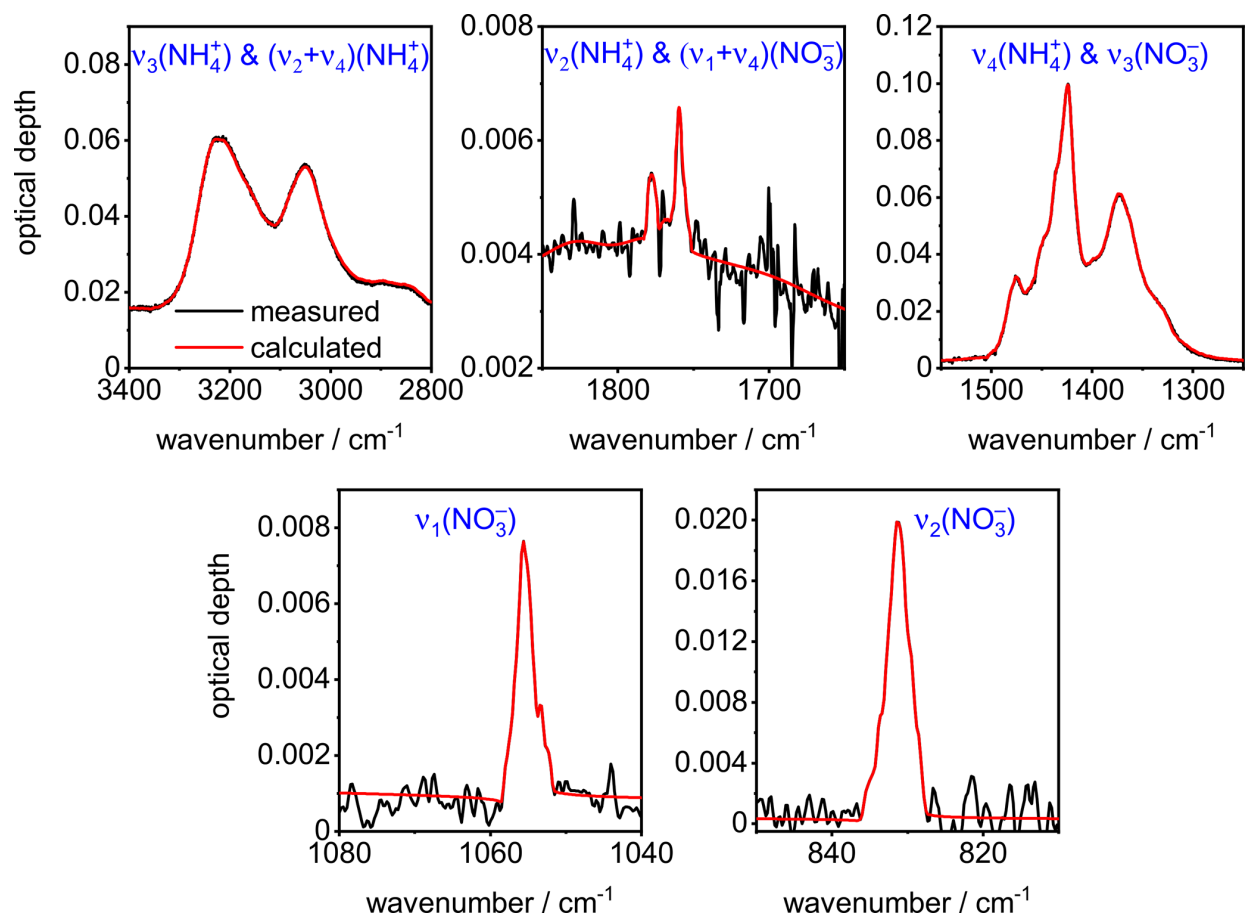

Figure A1. Comparison between the measured (black lines) and the computed (red lines) infrared extinction spectrum of crystalline AN particles in five different wavenumber regimes after convergence of the minimization algorithm with $n\left(\tilde{v}_{x}\right)=1.56, \chi=1.1$, and $\varphi=1$. The notation of the AN vibrational modes is according to Fernandes et al. (1979).

red lines) are shifted to higher wavenumbers in the measured particle spectrum (1424 and $1373 \mathrm{~cm}^{-1}$, dashed blue lines), accompanied by significant changes in their relative intensities. The intensity of the $1424 \mathrm{~cm}^{-1}$ band is disproportionately high compared to that of the $1373 \mathrm{~cm}^{-1}$ band, considering that the value of the imaginary refractive index is almost identical at both frequencies $(k \sim 1.4)$. However, the real refractive index at $1424 \mathrm{~cm}^{-1}$ is much lower than at $1373 \mathrm{~cm}^{-1}$, thereby better fulfilling the resonance condition for the manifestation of a Fröhlich, or surface mode, in the particle spectrum $(n \approx 0$ and $k \approx \sqrt{2}$ ) (Bohren and Huffman, 1983; Clapp and Miller, 1993). The same reasoning explains the frequency shift of the particle extinction bands towards higher wavenumbers compared to the maxima in the $k(\tilde{v})$ spectrum. Although this frequency shift leads to a reduction of the magnitude of the imaginary index $k$, the intensity of the particle extinction bands is enhanced due to the simultaneous decrease of the value for the real refractive index $n$, yielding a higher cross section due to a better match with the resonance condition. For a less intense absorption band like the $v_{2}\left(\mathrm{NO}_{3}^{-}\right)$mode at $831 \mathrm{~cm}^{-1}$, the amplitude of the anomalous dispersion feature in the $n(\tilde{v})$ spectrum is reduced and there are no explicit frequencies where the optical constants match the resonance condition. Therefore, the particle extinction band only experiences a minor frequency shift of about $0.4 \mathrm{~cm}^{-1}$ compared to the location of the absorption peak in the $k(\tilde{v})$ spectrum (Fig. B2).

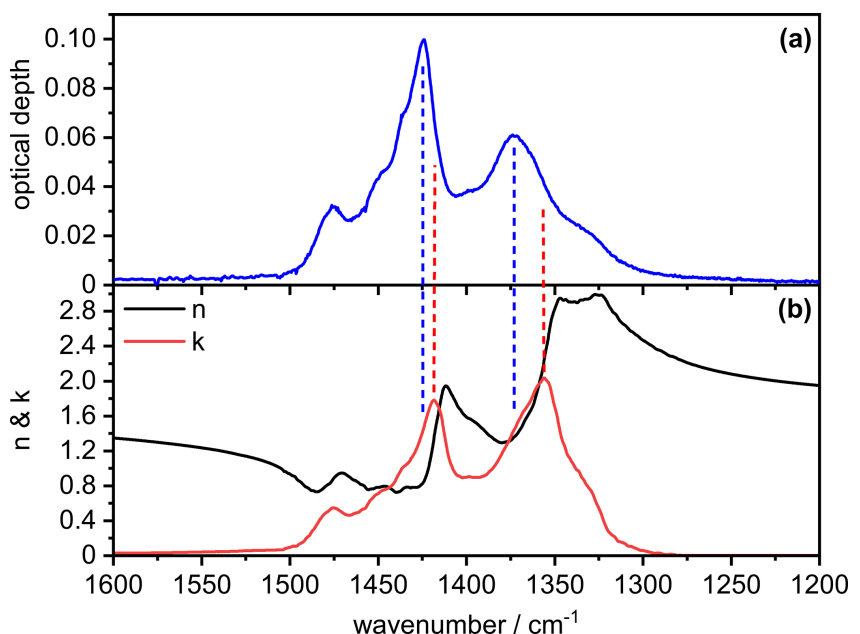

Figure B1. Comparison between the measured infrared extinction spectrum of crystalline AN particles (a) and the retrieved optical constants (b) in the $1200-1600 \mathrm{~cm}^{-1}$ wavenumber range. The retrieval was performed with the parameters $n\left(\tilde{v}_{x}\right)=1.56, \chi=1.1$, and $\varphi=1$. Vertical dashed lines indicate peak positions in the particle extinction spectrum (blue) and the $k(\tilde{v})$ spectrum (red). 


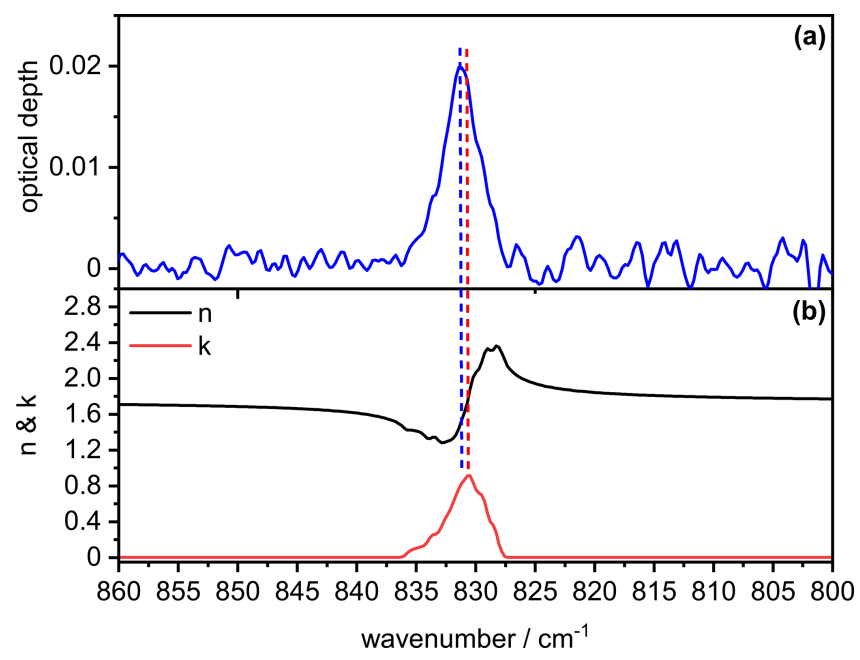

Figure B2. Comparison between the measured infrared extinction spectrum of crystalline AN particles (a) and the retrieved optical constants (b) in the $800-860 \mathrm{~cm}^{-1}$ wavenumber range. The retrieval was performed with the parameters $n\left(\tilde{v}_{x}\right)=1.56, \chi=1.1$, and $\varphi=1$. Vertical dashed lines indicate the peak position in the particle extinction spectrum (blue) and the $k(\tilde{v})$ spectrum (red).

In our sensitivity analysis (Sect. 3.2), we have investigated the response of the retrieved $k(\tilde{v})$ spectrum for the AN particles to a change of the parameter $\chi$, which controls the overall aerosol volume concentration, $V_{\text {aer }}$. We have observed that in the $1200-1500 \mathrm{~cm}^{-1}$ regime, the variation of $\chi$ did not induce a regular increase or decrease of the $k$ values over the whole frequency range (Fig. 5e). Obviously, the peak at $1418 \mathrm{~cm}^{-1}$ in the retrieved $k(\tilde{v})$ spectrum is much less influenced by a change in $V_{\text {aer }}$ than the absorption band at $1356 \mathrm{~cm}^{-1}$. As a tentative explanation, one might argue that the particle extinction band at $1424 \mathrm{~cm}^{-1}$, resulting from the $k$ maximum at $1418 \mathrm{~cm}^{-1}$, is less affected by $V_{\text {aer }}$, because its intensity is primarily governed by the strongly enhanced cross sections resulting from the match of the optical constants with the resonance condition. At $1356 \mathrm{~cm}^{-1}$, the resonance condition is of much less importance for the band intensity, meaning that the magnitude of the retrieved $k$ values at this frequency are more directly influenced by a change of $\chi$, that is, $V_{\text {aer }}$. 
Data availability. All refractive index data sets derived in this work can be downloaded from the KITopen repository, the central publication platform for KIT (Karlsruhe Institute of Technology) scientists, at https://doi.org/10.5445/IR/1000128813 (Wagner et al., 2021).

Author contributions. RW and MH conceptualized and supervised the project. RW, BT, AK, MH, HS, and JU performed the experiments. BT, MH, and RW analyzed the data. OM and TL were responsible for the project administration. BT, MH, and RW developed software and implemented computer codes for the data analysis. RW, BT, AK, and MH created the graphs for this article. RW and $\mathrm{MH}$ wrote the original manuscript draft. All authors contributed to review and editing.

Competing interests. The authors declare that they have no conflict of interest.

Acknowledgements. We gratefully acknowledge the continuous support by all members of the Engineering and Infrastructure group of IMK-AAF, in particular by Olga Dombrowski, Rainer Buschbacher, Tomasz Chudy, Steffen Vogt, and Georg Scheurig. This work has been funded by the Helmholtz-Gemeinschaft Deutscher Forschungszentren as part of the program "Atmosphere and Climate". Additional funding has been received by the French Erasmus+ agency.

Financial support. The article processing charges for this openaccess publication were covered by a Research Centre of the Helmholtz Association.

Review statement. This paper was edited by Andreas Macke and reviewed by two anonymous referees.

\section{References}

Ahrenkiel, R. K.: Modified Kramers-Kronig Analysis of Optical Spectra, J. Opt. Soc. Am., 61, 1651-1655, 1971.

Aroui, H., Orphal, J., and Tchana, F. K.: Fourier Transform Infrared Spectroscopy for the Measurement of Spectral Line Profiles, in: Fourier Transform - Materials Analysis, edited by: Salih, S. M., InTech, New York, 69-102, 2012.

Bohren, C. F. and Huffman, D. R.: Absorption and Scattering of Light by Small Particles, John Wiley \& Sons, Inc., New York, 1983.

Bothe, J. R. and Beyer, K. D.: Experimental determination of the $\mathrm{NH}_{4} \mathrm{NO}_{3} /\left(\mathrm{NH}_{4}\right)_{2} \mathrm{SO}_{4} / \mathrm{H}_{2} \mathrm{O}$ phase diagram, J. Phys. Chem. A, 111, 12106-12117, 2007.

Chellappa, R. S., Dattelbaum, D. M., Velisavljevic, N., and Sheffield, S.: The phase diagram of ammonium nitrate, J. Chem. Phys., 137, 064504, https://doi.org/10.1063/1.4733330, 2012.
Clapp, M. L. and Miller, R. E.: Shape Effects in the Infrared Spectrum of Ammonia Aerosols, Icarus, 105, 529-536, 1993.

Cziczo, D. J. and Abbatt, J. P. D.: Ice nucleation in $\mathrm{NH}_{4} \mathrm{HSO}_{4}$, $\mathrm{NH}_{4} \mathrm{NO}_{3}$, and $\mathrm{H}_{2} \mathrm{SO}_{4}$ aqueous particles: Implications for cirrus cloud formation, Geophys. Res. Lett., 28, 963-966, 2001.

Davis, R. D., Lance, S., Gordon, J. A., Ushijima, S. B., and Tolbert, M. A.: Contact efflorescence as a pathway for crystallization of atmospherically relevant particles, P. Natl. Acad. Sci. USA, 112, 15815-15820, 2015.

Dohm, M. T. and Niedziela, R. F.: Infrared complex refractive indices for nopinone, Geophys. Res. Lett., 31, L14109, https://doi.org/10.1029/2004g1019737, 2004.

Earle, M. E., Pancescu, R. G., Cosic, B., Zasetsky, A. Y., and Sloan, J. J.: Temperature-dependent complex indices of refraction for crystalline $\left(\mathrm{NH}_{4}\right)_{2} \mathrm{SO}_{4}$, J. Phys. Chem. A, 110, 13022-13028, 2006.

Fahey, D. W., Gao, R.-S., Möhler, O., Saathoff, H., Schiller, C., Ebert, V., Krämer, M., Peter, T., Amarouche, N., Avallone, L. M., Bauer, R., Bozóki, Z., Christensen, L. E., Davis, S. M., Durry, G., Dyroff, C., Herman, R. L., Hunsmann, S., Khaykin, S. M., Mackrodt, P., Meyer, J., Smith, J. B., Spelten, N., Troy, R. F., Vömel, H., Wagner, S., and Wienhold, F. G.: The AquaVIT-1 intercomparison of atmospheric water vapor measurement techniques, Atmos. Meas. Tech., 7, 3177-3213, https://doi.org/10.5194/amt-73177-2014, 2014.

Fairlie, T. D., Liu, H. Y., Vernier, J. P., Campuzano-Jost, P., Jimenez, J. L., Jo, D. S., Zhang, B., Natarajan, M., Avery, M. A., and Huey, G.: Estimates of Regional Source Contributions to the Asian Tropopause Aerosol Layer Using a Chemical Transport Model, J. Geophys. Res.-Atmos., 125, e2019JD031506, https://doi.org/10.1029/2019JD031506, 2020.

Fernandes, J. R., Ganguly, S., and Rao, C. N. R.: Infrared Spectroscopic Study of the Phase-Transitions in $\mathrm{CsNO}_{3}, \mathrm{RbNO}_{3}$ and $\mathrm{NH}_{4} \mathrm{NO}_{3}$, Spectrochim. Acta A, 35, 1013-1020, 1979.

$\mathrm{Gu}$, Y., Liao, H., and Bian, J.: Summertime nitrate aerosol in the upper troposphere and lower stratosphere over the Tibetan Plateau and the South Asian summer monsoon region, Atmos. Chem. Phys., 16, 6641-6663, https://doi.org/10.5194/acp-166641-2016, 2016.

Han, J. H., Hung, H. M., and Martin, S. T.: Size effect of hematite and corundum inclusions on the efflorescence relative humidities of aqueous ammonium nitrate particles, J. Geophys. Res.-Atmos., 107, 4086, https://doi.org/10.1029/2001JD001054, 2002.

Herrmann, M. J. and Engel, W.: Phase transitions and lattice dynamics of ammonium nitrate, Propellants Explos. Pyrot., 22, 143147, 1997.

Hinds, W. C.: Aerosol Technology, John Wiley \& Sons, Inc., New York, 1999.

Höpfner, M., Volkamer, R., Grabowski, U., Grutter, M., Orphal, J., Stiller, G., von Clarmann, T., and Wetzel, G.: First detection of ammonia $\left(\mathrm{NH}_{3}\right)$ in the Asian summer monsoon upper troposphere, Atmos. Chem. Phys., 16, 14357-14369, https://doi.org/10.5194/acp-16-14357-2016, 2016.

Höpfner, M., Ungermann, J., Borrmann, S., Wagner, R., Spang, R., Riese, M., Stiller, G., Appel, O., Batenburg, A. M., Bucci, S., Cairo, F., Dragoneas, A., Friedl-Vallon, F., Hünig, A., Johansson, S., Krasauskas, L., Legras, B., Leisner, T., Mahnke, C., Möhler, O., Molleker, S., Müller, R., Neubert, T., Orphal, J., Preusse, P., 
Rex, M., Saathoff, H., Stroh, F., Weigel, R., and Wohltmann, I.: Ammonium nitrate particles formed in upper troposphere from ground ammonia sources during Asian monsoons, Nat. Geosci., 12, 608-612, https://doi.org/10.1038/s41561-019-0385-8, 2019.

Jarzembski, M. A., Norman, M. L., Fuller, K. A., Srivastava, V., and Cutten, D. R.: Complex refractive index of ammonium nitrate in the 2-20- $\mu \mathrm{m}$ spectral range, Appl. Opt., 42, 922-930, https://doi.org/10.1364/Ao.42.000922, 2003.

Kelly, W. P. and McMurry, P. H.: Measurement of Particle Density by Inertial Classification of Differential Mobility Analyzer Generated Monodisperse Aerosols, Aerosol. Sci. Tech., 17, 199-212, https://doi.org/10.1080/02786829208959571, 1992.

Koch, T. G., Holmes, N. S., Roddis, T. B., and Sodeau, J. R.: Lowtemperature photochemistry of submicrometer nitric acid and ammonium nitrate layers, J. Phys. Chem., 100, 11402-11407, 1996.

Koop, T., Luo, B. P., Tsias, A., and Peter, T.: Water activity as the determinant for homogeneous ice nucleation in aqueous solutions, Nature, 406, 611-614, 2000.

Lau, W. K. M., Yuan, C., and Li, Z. Q.: Origin, Maintenance and Variability of the Asian Tropopause Aerosol Layer (ATAL): The Roles of Monsoon Dynamics, Sci. Rep.-UK, 8, 3960, https://doi.org/10.1038/s41598-018-22267-z, 2018.

Leisner, T. and Wagner, R.: Infrared Spectroscopy of Aerosol Particles, in: Fundamentals and Applications in Aerosol Spectroscopy, edited by: Signorell, R. and Reid, J. P., CRC Press, Boca Raton, 2011.

Milham, M. E., Frickel, R. H., Embury, J. F., and Anderson, D. H.: Determination of optical constants from extinction measurements, J. Opt. Soc. Am., 71, 1099-1106, 1981.

Mishchenko, M. I. and Travis, L. D.: Capabilities and limitations of a current FORTRAN implementation of the T-matrix method for randomly oriented, rotationally symmetric scatterers, J. Quant. Spectrosc. Ra., 60, 309-324, 1998.

Mishchenko, M. I., Travis, L. D., Kahn, R. A., and West, R. A.: Modeling phase functions for dustlike tropospheric aerosols using a shape mixture of randomly oriented polydisperse spheroids, J. Geophys. Res.-Atmos., 102, 16831-16847, 1997.

Möhler, O., Stetzer, O., Schaefers, S., Linke, C., Schnaiter, M., Tiede, R., Saathoff, H., Krämer, M., Mangold, A., Budz, P., Zink, P., Schreiner, J., Mauersberger, K., Haag, W., Kärcher, B., and Schurath, U.: Experimental investigation of homogeneous freezing of sulphuric acid particles in the aerosol chamber AIDA, Atmos. Chem. Phys., 3, 211-223, https://doi.org/10.5194/acp-3211-2003, 2003.

Murphy, D. M. and Koop, T.: Review of the vapour pressures of ice and supercooled water for atmospheric applications, Q. J. Roy. Meteor. Soc., 131, 1539-1565, 2005.

Norman, M. L., Qian, J., Miller, R. E., and Worsnop, D. R.: Infrared complex refractive indices of supercooled liquid $\mathrm{HNO}_{3} / \mathrm{H}_{2} \mathrm{O}$ aerosols, J. Geophys. Res.-Atmos., 104, 30571-30584, 1999.

Ohta, K. and Ishida, H.: Comparison among Several Numerical Integration Methods for Kramers-Kronig Transformation, Appl. Spectrosc., 42, 952-957, 1988.

Ossenkopf, V., Henning, T., and Mathis, J. S.: Constraints on Cosmic Silicates, Astron. Astrophys., 261, 567-578, 1992.

Press, W. H., Teukolsky, S. A., Vetterling, W. T., and Flannery, B. P.: Numerical Recipes in C: The Art of Scientific Computing, Cambridge University Press, Cambridge, 1992.
Rouleau, F. and Martin, P. G.: Shape and Clustering Effects on the Optical Properties of Amorphous Carbon, Astrophys. J., 377, 526-540, 1991.

Schlenker, J. C., Malinowski, A., Martin, S. T., Hung, H. M., and Rudich, Y.: Crystals formed at $293 \mathrm{~K}$ by aqueous sulfatenitrate-ammonium-proton aerosol particles, J. Phys. Chem. A, 108, 9375-9383, 2004.

Schlenker, J. C. and Martin, S. T.: Crystallization pathways of sulfate-nitrate-ammonium aerosol particles, J. Phys. Chem. A, 109, 9980-9985, 2005.

Schnaiter, M., Büttner, S., Möhler, O., Skrotzki, J., Vragel, M., and Wagner, R.: Influence of particle size and shape on the backscattering linear depolarisation ratio of small ice crystals - cloud chamber measurements in the context of contrail and cirrus microphysics, Atmos. Chem. Phys., 12, 10465-10484, https://doi.org/10.5194/acp-12-10465-2012, 2012.

Segal-Rosenheimer, M. and Linker, R.: Impact of the non-measured infrared spectral range of the imaginary refractive index on the derivation of the real refractive index using the Kramers-Kronig transform, J. Quant. Spectrosc. Ra., 110, 1147-1161, 2009.

Segal-Rosenheimer, M., Dubowski, Y., and Linker, R.: Extraction of optical constants from mid-IR spectra of small aerosol particles, J. Quant. Spectrosc. Ra., 110, 415-426, 2009.

Shen, Z. X., Kuok, M. H., Tang, S. H., and Sherman, W. F.: Infrared Study of Phases III, IV and V of $\mathrm{NH}_{4} \mathrm{NO}_{3}$, Spectrochim. Acta A, 49, 21-29, 1993.

Shilling, J. E., Fortin, T. J., and Tolbert, M. A.: Depositional ice nucleation on crystalline organic and inorganic solids, J. Geophys. Res.-Atmos., 111, D12204, https://doi.org/10.1029/2005JD006664, 2006.

Signorell, R. and Luckhaus, D.: Aerosol spectroscopy of dihydroxyacetone: Gas phase and nanoparticles, J. Phys. Chem. A, 106, 4855-4867, 2002.

Théorêt, A. and Sandorfy, C.: Infrared Spectra and Crystalline Phase Transitions of Ammonium Nitrate, Can. J. Chem., 42, 5762, 1964.

Thomason, L. W. and Vernier, J.-P.: Improved SAGE II cloud/aerosol categorization and observations of the Asian tropopause aerosol layer: 1989-2005, Atmos. Chem. Phys., 13 , 4605-4616, https://doi.org/10.5194/acp-13-4605-2013, 2013.

Vernier, J. P., Thomason, L. W., and Kar, J.: CALIPSO detection of an Asian tropopause aerosol layer, Geophys. Res. Lett., 38, L07804, https://doi.org/10.1029/2010GL046614, 2011.

Vernier, J. P., Fairlie, T. D., Natarajan, M., Wienhold, F. G., Bian, J., Martinsson, B. G., Crumeyrolle, S., Thomason, L. W., and Bedka, K. M.: Increase in upper tropospheric and lower stratospheric aerosol levels and its potential connection with Asian pollution, J. Geophys. Res.-Atmos., 120, 1608-1619, 2015.

Vernier, J. P., Fairlie, T. D., Deshler, T., Ratnam, M. V., Gadhavi, H., Kumar, B. S., Natarajan, M., Pandit, A. K., Raj, S. T. A., Kumar, A. H., Jayaraman, A., Singh, A. K., Rastogi, N., Sinha, P. R., Kumar, S., Tiwari, S., Wegner, T., Baker, N., Vignelles, D., Stenchikov, G., Shevchenko, I., Smith, J., Bedka, K., Kesarkar, A., Singh, V., Bhate, J., Ravikiran, V., Rao, M. D., Ravindrababu, S., Patel, A., Vernier, H., Wienhold, F. G., Liu, H., Knepp, T. N., Thomason, L., Crawford, J., Ziemba, L., Moore, J., Crumeyrolle, S., Williamson, M., Berthet, G., Jegou, F., and Renard, J. B.: BATAL: The Balloon Measurement Campaigns of the Asian 
Tropopause Aerosol Layer, B. A. Meteor. Soc., 99, 955-973, 2018.

Wagner, R., Benz, S., Möhler, O., Saathoff, H., and Schurath, U.: Probing ice clouds by broadband mid-infrared extinction spectroscopy: case studies from ice nucleation experiments in the AIDA aerosol and cloud chamber, Atmos. Chem. Phys., 6, 47754800, https://doi.org/10.5194/acp-6-4775-2006, 2006a.

Wagner, R., Bunz, H., Linke, C., Möhler, O., Naumann, K. H., Saathoff, H., Schnaiter, M., and Schurath, U.: Chamber Simulations of Cloud Chemistry: The AIDA Chamber, Proceedings of the NATO Advances Research Workshop on Environmental Simulation Chambers: Application to Atmospheric Chemical Processes, Zakopane, Poland, 1-4 October 2004, 67-82, 2006b.

Wagner, R., Linke, C., Naumann, K. H., Schnaiter, M., Vragel, M., Gangl, M., and Horvath, H.: A review of optical measurements at the aerosol and cloud chamber AIDA, J. Quant. Spectrosc. Ra., 110, 930-949, 2009.

Wagner, R., Höhler, K., Huang, W., Kiselev, A., Möhler, O., Mohr, C., Pajunoja, A., Saathoff, H., Schiebel, T., Shen, X. L., and Virtanen, A.: Heterogeneous ice nucleation of $\alpha$-pinene SOA particles before and after ice cloud processing, J. Geophys. Res.Atmos., 122, 4924-4943, 2017.

Wagner, R., Bertozzi, B., Höpfner, M., Höhler, K., Möhler, O., Saathoff, H., and Leisner, T.: Solid ammonium nitrate aerosols as efficient ice nucleating particles at cirrus temperatures, J. Geophys. Res.-Atmos., 125, e2019JD032248, https://doi.org/10.1029/2019JD032248, 2020.

Wagner, R., Testa, B., Höpfner, M., Kiselev, A., Möhler, O., Saathoff, H., Ungermann, J., and Leisner, T.: Data sets for the research article "High-resolution optical constants of crystalline ammonium nitrate for infrared remote sensing of the Asian Tropopause Aerosol Layer" by Wagner et al. (2021) in Atmospheric Measurement Techniques, KITopen, https://doi.org/10.5445/IR/1000128813, 2021.
Wang, M., Kong, W., Marten, R., He, X.-C., Chen, D., Pfeifer, J., Heitto, A., Kontkanen, J., Dada, L., Kürten, A., Yli-Juuti, T., Manninen, H. E., Amanatidis, S., Amorim, A., Baalbaki, R., Baccarini, A., Bell, D. M., Bertozzi, B., Bräkling, S., Brilke, S., Murillo, L. C., Chiu, R., Chu, B., De Menezes, L.-P., Duplissy, J., Finkenzeller, H., Carracedo, L. G., Granzin, M., Guida, R., Hansel, A., Hofbauer, V., Krechmer, J., Lehtipalo, K., Lamkaddam, H., Lampimäki, M., Lee, C. P., Makhmutov, V., Marie, G., Mathot, S., Mauldin, R. L., Mentler, B., Müller, T., Onnela, A., Partoll, E., Petäjä, T., Philippov, M., Pospisilova, V., Ranjithkumar, A., Rissanen, M., Rörup, B., Scholz, W., Shen, J., Simon, M., Sipilä, M., Steiner, G., Stolzenburg, D., Tham, Y. J., Tomé, A., Wagner, A. C., Wang, D. S., Wang, Y., Weber, S. K., Winkler, P. M., Wlasits, P. J., Wu, Y., Xiao, M., Ye, Q., ZaunerWieczorek, M., Zhou, X., Volkamer, R., Riipinen, I., Dommen, J., Curtius, J., Baltensperger, U., Kulmala, M., Worsnop, D. R., Kirkby, J., Seinfeld, J. H., El-Haddad, I., Flagan, R. C., and Donahue, N. M.: Rapid growth of new atmospheric particles by nitric acid and ammonia condensation, Nature, 581, 184-189, https://doi.org/10.1038/s41586-020-2270-4, 2020.

Yu, P. F., Rosenlof, K. H., Liu, S., Telg, H., Thornberry, T. D., Rollins, A. W., Portmann, R. W., Bai, Z. X., Ray, E. A., Duan, Y. J., Pan, L. L., Toon, O. B., Bian, J. C., and Gao, R. S.: Efficient transport of tropospheric aerosol into the stratosphere via the Asian summer monsoon anticyclone, P. Natl. Acad. Sci. USA, 114, 6972-6977, https://doi.org/10.1073/pnas.1701170114, 2017.

Zasetsky, A. Y., Khalizov, A. F., Earle, M. E., and Sloan, J. J.: Frequency Dependent Complex Refractive Indices of Supercooled Liquid Water and Ice Determined from Aerosol Extinction Spectra, J. Phys. Chem. A, 109, 2760-2764, 2005.

Zasetsky, A. Y., Earle, M. E., Cosic, B., Schiwon, R., Grishin, I. A., McPhail, R., Pancescu, R. G., Najera, J., Khalizov, A. F., Cook, K. B., and Sloan, J. J.: Retrieval of aerosol physical and chemical properties from mid-infrared extinction spectra, J. Quant. Spectrosc. Ra., 107, 294-305, 2007. 